defensive nature, it follows that antibiotics themselves have a function in suppressing other species than those forming them and thus securing a more liberal supply of nutrient. "Nature red in tooth and claw," an expression intended to refer only to the animal kingdom, has thus an equivalent even among the lowest plants-a forbidding thought to the believer in peaceful co-existence as a natural way of life.

\section{Spread of Influenza}

The prognosis of an individual patient's disease is always difficult even with a straightforward infection like influenza. Likewise to predict the appearance and course of epidemics is chancy. Nevertheless international co-operation, particularly through the World Health Organization's Reference Centres, has given us a fairly complete picture of what is happening to the viruses causing influenza epidemics.

In 1947 and in 1957 completely new serotypes of influenza appeared-types A1 and A2-and these spread across the world, producing large epidemics. More epidemics followed in later years, and comparison shows that the virus strains have changed the antigens on their coats appreciably. This is presumably because new variants have a better chance of survival against the antibody induced by the last variety of influenza. Two distinct new antigenic modifications have occurred since the first A2 (Asian 'flu) viruses appeared, and have usually been associated with new epidemics. ${ }^{1-6}$

However, whether a virus spreads in a country depends not only on the "newness" or otherwise of its antigens but on the antibodies the inhabitants are carrying. Influenza $A$ in Britain tends to recur at about two-year intervals, ${ }^{7}$ but recent years have shown exceptions to this rule (which is not followed in other parts of the world). It has therefore been suggested that if we know the immune status of the population of a country, in particular if we know the number of people carrying antibody against the current strain, then we may be able to predict an epidemic, and perhaps forestall it by vaccinating with the virus for which the population has no antibody. When new strains have appeared such studies have been made, and they are easy to interpret. In the 1957 pandemic only the very old had antibody against the $A 2$ virus strain, and everyone else had no antibody and was susceptible. In the interpandemic period serological surveys are not so easy. Such studies have been made abroad, usually with the haemagglutination-inhibition tests to detect the antibody. ${ }^{8}$ The first of such studies from Great Britain are reported in this issue of the B.M.f. (p. 80). Dr. Marguerite Pereira and her colleagues report that sera were collected from October 1965 to May 1966 from routine blood specimens examined in public health laboratories, and were tested by a specific complement-fixation test for antibodies against the surface (V) antigens of recently isolated strains of influenza A2 and B. Only about one-half of the preschool children had antibody against influenza $\mathbf{A}$ and a quarter against influenza $B$, but over half the school-age children and adults had antibody. The peak level of antibody to recent strains was in the age group 15-24, possibly because they had been heavily affected by influenza and also because they had relatively little experience of the antigens of the earlier influenza serotypes which "condition" the immune mechanism to produce antibody against the earlier types rather than against the recent ones. This phenomenon was called "original antigenic sin," and the mechanism has recently been studied by reproducing the phenomenon in rabbits injected successively with different influenza virus vaccines. ${ }^{10}$ It is thought to occur when clones of antibodyproducing cells proliferate after the first antigenic experience of the virus, and are restimulated when partly cross-reacting antigens are met. But if large amounts of such new antigens are given they may not be adequately dealt with and may stimulate the formation of a new clone.

The second study, by Dr. G. C. Schild and Professor C. H. Stuart-Harris, appears at page 82. They used sera collected from children in South Yorkshire in three periods-namely in 1965, early 1966, and the winter of 1966-7. There was an outbreak of influenza due to both $A 2$ and $B$ viruses in the area in 1966, and the study therefore sheds light on the response of the "antigenically inexperienced" part of the population. In general antibody was less common and of lower titre in the younger children. Though most children had antibody against the 1964 influenza A2 before the epidemic, there was by 1966 a marked increase in the number with high titres, presumably as a result of natural exposure. Fewer children had antibodies against the 1965 influenza B strain, but the proportion of these with medium or low titres increased during the epidemic. The lowest frequency of antibodies was found in each case against the most recently isolated strain of influenza-that is, the 1966 strain-though by tests with sera prepared in the laboratory their antigenic composition did not seem to be particularly different from the viruses isolated one or two years before. The authors suggest, in fact, that tests with children's sera may be the most delicate way of distinguishing between closely related influenza viruses, and certainly differences shown with human sera may well be important in epidemiology. On the other hand, sera from adults would probably distinguish between viruses less sharply than animal sera do.

The results of the survey by Dr. Pereira and her colleagues show that many people have antibody against the current influenza virus strains, and the authors say we are unlikely to have an epidemic due to these or similar strains. This is reassuring, but it leaves another question unanswered. How

1 Robinson, R. Q., Progr. med. Virol., 1964, 6; 82.

2 Isaacs, A., Hart, R. J. C., and Law, V. G., Bull. Wld Hlth Org., 1962, 26, 253.

Morris, J. A., Hatano, M., Robinson, R. Q., Aulisio, C. G., and Smadel, J. E., Proc. Soc. exp. Biol. (N.Y.), 1963, 114, 406.

Weinberger, H. L., Buescher, E. L., McCown, J., and Gauld, J. R., ibid., 1963, 114, 413.

Pereira, H. G., Pereira, M. S., and Law, V. G., Bull. Wld Hlth Org., $1964,31,129$.

Zhdanov, V. M., Zaxstelskaya, L. Y., Nesterenko, M. K., Yakhno M. A., and Isachenko, V. A., Amer. F. Epidemiol., 1967, 85, 175.

Stuart-Harris, C. H., Influenza and Other Virus Infections of the Respiratory Tract, 2nd ed., 1965. London.

- Pešek, J., and Vobecký, J., $\mathfrak{f}$. Hyg. Epidem. (Praha), 1964, 8, 21

- Davenport, F. M., and Hennessy, A. V., F. exp. Med., 1957, 106, 835

10 Fazekas de St. Groth, S., and Webster, R. G., ibid., 1966, 124, 331.

11 Magill, T. P., ibid., 1955, 102, 279.

2. Schäfer, W., Z. Naturforsch., 1955, $10 \mathrm{~b}, 81$.

Pereira, H. G., Tůmová, B., and Law, V. G., Communicable Disease Center, Zoonoses Surveillance Report No. 5, p. 26, 1965. Atlanta.

- Tůmová, B., and Fišerová-Sovinová, O., Bull.' Wild Hlth Org., 1959, $20,445$.

- Waddell, G. H., Teigland, M. B., and Sigel, M. M., F. Amer. vet. med. Ass., 1963, 143, 587.

- Kasel, J. A., Alford, R. H., Knight, V., Waddell, G. H., and Sigel, M. M., Nature (Lond.), 1965, 206, 4 i.

Schild, G. C., and Stuart-Harris, C. H., f. Hyg. (Lond.), 1965, 63, 479.

Minuse, E., McQueen, J. L., Davenport, F. M., and Francis, T., iun., f. Immunol., 1965, 94, 563.

10 Kloene, W., et al., Virology, 1966, 28, 774.

" Green, I. J., Hung, S. C., Yu, P. S., Lee, G. W., and Pereira, H. G., Amer 7. Hyg., $1964.79,107$.

2 Schulman, J. L., and Kilbourne, E. D., f. exp. Med., 1963, 118, 257.

22 In Proceedings of the Third International Biometeorological Congress, ed. S. W. Tromp and W. H. Weike, 1966. Oxford.

s Schulman, J. L., f. exp. Med., 1967, 125, 467 
long will it be before the virus changes sufficiently to evade the immune barrier which the human herd has raised against it ?

Attempts to produce the "next" variant in laboratory animals have not been successful. ${ }^{11}$ In recent years it has become clear that influenza $A$ and $B$ viruses can in fact be isolated from cases of respiratory disease between epidemics, in periods when clinical or epidemiological observations such as the frequency of deaths from pneumonia, sickness claims, or outbreaks in institutions or local communities do not show that an epidemic is in progress. Thus, though the virus may seem to have disappeared, it can be found if looked for sufficiently thoroughly. However, so far no new serotype has been caught in the act of antigenic evolution.

An even less predictable event is the appearance of radically new influenza viruses, such as the Asian influenza virus. For many years it was thought that they might come from an animal reservoir. Unfortunately, in the best-studied example, that of influenza in American pigs, it seemed more likely that the virus had gone from man to pig in the 1918 epidemic rather than the reverse. But it does now provide a good example of an influenza virus which maintains itself in animals. Its life cycle, involving earthworms and nematodes, is rather extraordinary, but it is apparently independent of man-except that it is man who keeps the pigs. However, in recent years we have learnt much more about influenza viruses in animals. It was discovered in 1955 that the longknown fowl plague virus is actually an influenza $A$ virus, ${ }^{12}$ and since then that there are also other antigenically distinct influenza A viruses affecting ducks, ${ }^{13}$ turkeys, terns, and game birds, and two different serotypes have been recovered from horses both in Europe ${ }^{14}$ and in North America. ${ }^{15}$ Human beings have been infected experimentally with one of the horse viruses, but large doses were used and only one volunteer became sick. ${ }^{16}$

Antibody against one of the horse viruses has been found in the sera of old persons. ${ }^{17} 18$ It is difficult to interpret this. But if man was infected in the last century with a virus related to one now infecting horses, that does not prove that it came from horses or from any other animal. Furthermore, there is no well-documented instance of an epidemic beginning in animals and spreading to man, though it might be a rare event and also take place in economically impoverished places where man and animals live close together and opportunities for precise observation are few. There are examples of almost completely new antigenic serotypes of influenza $\mathbf{B}$ which produced local outbreaks of disease in man but did not spread across continents as they were expected to do. ${ }^{1920}$ They apparently lacked something, perhaps the ability to survive in air and so spread rapidly, which would have made them into completely successful epidemic strains. So animal influenza viruses which would ordinarily grow rather poorly in the cells of man would, if the theory were correct, be likely to produce a few cases more often than a distinct epidemic. Any possible examples should be quickly reported and investigated by expert virologists.

Recent experiments on mice ${ }^{2122}$ have shown that the virus is transmitted as airborne droplets, and that the rate of transmission can be reduced by increasing ventilation and modified by the temperature and humidity of the air. Some viruses are much better "spreaders" than others, though it is still not clear why they are. Further experiments, just described, ${ }^{23}$ show that though serious disease can be prevented by vaccinating mice with live or killed vaccine the live vaccine also reduces the ability to transmit infection to other animals when mice are reinfected, while mice protected with killed vaccine can still act as transmitters.

The epidemiology of influenza is rather like the study of economics: it does not tell us what is going to happen so much as why things happen after they have done so. Consequently a prediction for the coming winter in Britain must be based on a balance of probabilities. Two years ago we had influenza $A 2$ and $B$, so we might expect influenza A2 to return this year, as it seems to have done in the southern hemisphere during our summer. There is no sign of a radically new antigenic type of virus, and many people carry antibodies against the current types. So if an epidemic comes it is likely to be mild.

\section{Postoperative Gas Gangrene}

It has recently been reported in the daily press that two cases of gas gangrene, one of them fatal, have followed amputation through the thigh in a Birmingham hospital, and that an operating-theatre suite has consequently been closed. Some comments on this occurrence ${ }^{1}$ refer to the ubiquity of pathogenic bacteria in the hospital environment and the necessity for greater and very expensive precautions in order to reduce the risk so entailed. A further report ${ }^{2}$ concerns three cases of gas gangrene at a London hospital, but gives no information about the circumstances in which they arose.

No lessons can be drawn from these two episodes until a full account of them is available, but there are certain facts about the causation of this infection, and particularly with regard to its source, which apparently deserve to be more widely known. The organism almost invariably causing postoperative gas gangrene is Clostridium welchii. It is a normal inhabitant of the bowel of man and animals, and almost always to be found in soil, dirt, and dust. Its spores are capable of prolonged survival. Their exclusion from the hospital environment is impossible. For instance, E. J. L. Lowbury and H. A. Lilly ${ }^{3}$ found them in every sample of air examined in a hospital, including that of operatingtheatres. Moreover, the organism is not uncommonly present in the exudate from traumatic wounds or burns which are the seat of nothing more than transient suppuration. It is thus implanted in many traumatic wounds and probably in a substantial proportion of surgical wounds without giving rise to the acute necrosing myositis with formation of gas which is gas gangrene.

What, then, is the missing factor which ensures these patients' safety ? It is simply that the tissues involved have an adequate blood supply and thus an oxygen tension in which clostridia cannot grow. The spores of an anaerobe cannot even germinate in a tissue normally supplied with blood. In traumatic gas gangrene the infection originates in muscle which has been crushed or cut off from its blood supply. Only profuse growth of clostridia in such an area can create conditions in which normal muscle can subsequently be invaded.

For three reasons gas gangrene is more likely to follow thigh amputation for obliterative arterial disease than other

\footnotetext{
Observer, 1 October 1967.

2 The Times, 5 October 1967.

s Lowbury, E. J. and Lilly, H. A. 7. Hyg. (Lond.), 1958, 56, 169.

- Williams, R. E. O., Blowers, R., Garrod, L. P., and Shooter, R. A. Hospital Infection, 2nd d., 1966. London.

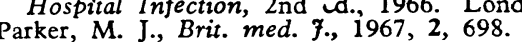

6 Price, D. J. E., and Shooter, R. A., ibid., 1964, 2, 1176.
} 